\title{
Laparoscopic Management of Benign Ovarian Cysts: Three Years Experience in Combined Military Hospital, Dhaka
}

\author{
Chisty $\mathrm{S}^{1}$, Chowdhury $\mathrm{L}^{2}$ \\ DOI: https:/ / doi.org/ 10.3329/ jafmc.v15i2.50840
}

\begin{abstract}
Introduction: Ovarian cyst is a common clinical problem affecting women of all age groups. Laparoscopy should be considered as an alternative to laparotomy in the management of benign ovarian cysts. The aim of this study is to determine the safety, efficacy and outcome of laparoscopic surgery for benign ovarian cysts.
\end{abstract}

Materials and Method: A Prospective observational study has been carried out during the period of Jun 2016 to May 2019 in combined military hospital Dhaka. Total 107 patients who underwent laparoscopic surgery for benign ovarian cysts during this period were included in this study.

Results: The maximum number of women was in the 21-30 year- old age groups. Majority were endometriotic cyst (45.79\%) followed by perovarian cysts (14.01\%) and dermoid cysts (12.14\%). The diameter ranges from $4-15 \mathrm{~cm}$.and most of them were unilateral (91.5\%). Ovarian cystectomy is the most commonly performed procedure (88.78\%). Mean duration of surgery was 62.75 minutes. Complications were also fewer like postoperative fever (22.2\%), and trocar site infection.(11.2\%). None of the pts required conversion to laparotomy.

Conclusion: With a careful preoperative screening the laparoscopic surgery is a safe and effective treatment for benign ovarian cyst Laparoscopic surgery seems to offer significant advantages such as less adverse effects, reduced hospital stay and better quality of life.

Key-words: Benign ovarian cyst, Laparoscopic surgery, Surgical outcome.

\section{Introduction}

An ovarian cyst is a common gynecological problem which a gynecologist has to treat..Benign ovarian cyst such as endometrioma, dermoid cyst, serus or mucinous cyst adenoma is frequently seen in young and reproductive age group. It is estimated that approximately $10 \%$ of women in United States will undergo surgical procedure for a suspected ovarian neoplasm during their lifetime ${ }^{1}$. Several surgical modalities can be performed to manage benign ovarian cyst. Laparoscopic surgery has become the gold standard approach in the management of benign ovarian cyst2. During the last decades laparoscopic treatment has been established as a routine method of benign ovarian masses $^{3}$. The benefit of laparoscopy includes reduced postoperative analgesic requirement, earlier mobilization and reducing chance of deep venous thrombosis, cosmetic advantages, earlier discharge from the hospital and return to normal activity4.

Laparoscope facilitates illumination and magnification of the pelvis. Furthermore, one is able to obtain a panoramic view of the pelvis for an easier assessment of the extent of the disease. Clinical assessment of the patient with a cystic ovarian mass plays an important role in the management of ovarian cyst. According to the current evidence the parameter which should be examined preoperatively in order to exclude the possibility of a malignancy are the following like morphology of the ovarian cyst (septations papillary projection, echogenicitty and volume) and characteristics which could be evaluated by using transvaginal ultrasonography. Doppler ultrasonography could also be helpful by examining the vuscularity of the mass to exclude possibilities of malignancy. In addition, tumour markers like CA19-9, CA-125 should be done to exclude the possibilities of malignancy ${ }^{5}$. The purpose of the study is to observe the outcome of laparoscopy in the management of benign ovarian cysts.

\section{Materials and Methods}

This prospective observational study was carried out in the department of obstetrics \& gynaecology department of combined military hospital Dhaka during the period from February 2018 to January 2019. Total 107 patients with ovarian cysts in whom there were no signs of malignancy preoperatively from history, clinical examination and radiological findings and tumour marker level are included in this study. Excluding criteria were known contraindication for laparoscopy such as medical reasons as well as ultrasonographic evidence of malignancy like, presence of thick septation, papillary projection, low vascular resistance and pulsatility index. All the operations were done under $\mathrm{G} / \mathrm{A}$. After creating prior pneumoperitoneum with veress needle one $10 \mathrm{~mm}$ and two $5 \mathrm{~mm}$ trocars were introduced in each patient. A third suprapubic $5 \mathrm{~mm}$ port often used for better dissection. Curved scissors and plain grasping forceps were used for dissection in most of the cases. For haemostasis bipolar coagulation were used. Clinical data were collected from patients' history, clinical findings, USG and tumour markers reports. Per-operative and postoperative complications were recorded. The number of postoperative days spent in hospital was also noted Patients were followed up up-to 3 months for delayed complication. A preformed data sheets were used to collect all the data. Histopathological reports of all the cases were also obtained, Data were analyzed using SPSS.

\section{Results}

Total 107 patients underwent laparoscopic surgery for benign ovarian cysts during the study period of 3 years from February 2018 to January 2019. Most of them were in the age group of $16-30$ years $21(19.6 \%)$ patients were asymptomatic and presented with USG diagnosis of ovarian cyst, 47(43.92\%) women came with history of infertility, 39(36.44\%) women were presented with dysmenorroea, 42(39.25\%) women came with dull aching pelvic pain, and 24(22.42\%) patients reported with acute abdominal pain (Table-I). Size of the ovaian cysts were ranged from $4-14 \mathrm{~cm}$ and maximum number of patients had cyst size of 4-6 cm. Unilateral salpingooophorectomy was done in 11(10.28\%) patients' andcyst aspiration 
in one patient. Adhesiolysis were done as an additional procedure in $32(22.9 \%)$ cases. Per-operatively it was found that $93(86.91 \%)$ cases were ovarian in origin, and 14(13.08\%) cases were perovarian cysts. Among the ovarian cysts endometrioma were most common findings (45.79\%) followed by dermoid cysts (12.14\%). Peroperative complications were very less. Rupture of the cysts prior to drainage occurred in $18(16.82 \%)$ cases specially in cases of endometriomas during dissection and in $89(83.17 \%)$ cases cysts were intact before aspiration. Excessive bleeding had occurred from the ovary during cystectomy in $6(5.6 \%)$ patients and two of them required one unit of blood transfusion per-operatively. Postoperative complications were fever in 24(22.42\%) women, port site infection in $12(11.2 \%)$ patients. There was no bowel or urinary tract injury. In all cases diagnosis were confirmed by histopathology. None of the patients found to have malignancy. Histology confirmed endometrioma, in 49(45.79\%) patients, dermoid cyst in 13(12.14\%) women serous cystadenoma in 12(11.2\%) cases, mucinous cystadenoma in 5(4.67\%) patients, perovarian cyst in 15(14.01\%) patients, corpus luteal cyst. in 7(6.54\%) and simple follicular cyst in $6(6.54 \%)$ cases (Table-II). Tumour markers were within normal limit in most of the cases (83.1\%) except in few cases (22.42\%) of suspected endometrioma CA-125 were slightly elevated, 95(88.78\%) women underwent ovarian cystectomy (Table-III). Mean operating time were 62.75 minutes, Mean estimated blood loss were $39.62 \mathrm{ml}$. Mean reduction of $\mathrm{Hb}$ level in the $2^{\text {nd }}$ post-operative day were $0.7 \mathrm{gm} / \mathrm{dl}$. Mean hospital stay were 4.43 days (Table-IV).

Table-I: Demographic characteristics of patients $(n=107)$

\begin{tabular}{|c|c|c|c|}
\hline \multicolumn{2}{|c|}{ Characteristics } & Frequency & Percentage \\
\hline \multirow{4}{*}{ Age } & $10-20$ & 6 & 5.60 \\
\hline & $21-30$ & 68 & 63.55 \\
\hline & $31-40$ & 31 & 28.97 \\
\hline & $41-50$ & 2 & 1.8 \\
\hline \multirow{5}{*}{ Parity } & Para-0 & 33 & 30.84 \\
\hline & Para-1 & 26 & 24.29 \\
\hline & Para-2 & 23 & 21.49 \\
\hline & Para-3 & 3 & 2.80 \\
\hline & Para-4 & 0 & 0 \\
\hline \multirow{7}{*}{$\begin{array}{l}\text { Clinical } \\
\text { presentation }\end{array}$} & Asymptomatic & 21 & 19.62 \\
\hline & $\begin{array}{l}\text { Dull aching } \\
\text { abdominal } \\
\text { pain }\end{array}$ & 42 & 39.25 \\
\hline & $\begin{array}{c}\text { Acute } \\
\text { abdominal } \\
\text { pain }\end{array}$ & 24 & 22.42 \\
\hline & Dysmenorroea & 39 & 36.44 \\
\hline & Infertility & 47 & 43.92 \\
\hline & $\begin{array}{l}\text { Abdominal } \\
\text { Lump }\end{array}$ & 1 & 0.93 \\
\hline & $\begin{array}{c}\text { Abnormal } \\
\text { uterine } \\
\text { bleeding }\end{array}$ & 2 & 1.86 \\
\hline
\end{tabular}

Table-Il: Size of the ovarian cysts $(\mathrm{n}=107)$

\begin{tabular}{|c|c|c|c|}
\hline \multicolumn{2}{|c|}{ Characteristics } & Frequency & Percentage \\
\hline \multirow{4}{*}{$\begin{array}{l}\text { Size of } \\
\text { ovarian cyst }\end{array}$} & $4-6 \mathrm{~cm}$ & 53 & 49.53 \\
\hline & $7-9 \mathrm{~cm}$ & 44 & 41.12 \\
\hline & $10-12 \mathrm{~cm}$ & 9 & 8.41 \\
\hline & $13-15 \mathrm{~cm}$ & 1 & 0.93 \\
\hline \multirow{3}{*}{$\begin{array}{l}\text { Name of } \\
\text { operation }\end{array}$} & Cystectomy & 95 & 88.78 \\
\hline & $\begin{array}{l}\text { Salpingo- } \\
\text { oophorectomy }\end{array}$ & 11 & 10.28 \\
\hline & Cyst aspiration & 1 & 0.93 \\
\hline \multirow{5}{*}{$\begin{array}{l}\text { Name of } \\
\text { surgery }\end{array}$} & Adhesiolysis & 32 & 29.9 \\
\hline & Myomectomy & 1 & 0.93 \\
\hline & Appendisectomy & 2 & 1.86 \\
\hline & $\begin{array}{l}\text { Tubal } \\
\text { sterillization }\end{array}$ & 1 & 0.93 \\
\hline & Cholecystectomy & 1 & 0.93 \\
\hline \multirow{7}{*}{$\begin{array}{l}\text { Histological } \\
\text { type }\end{array}$} & Endometrioma & 49 & 45.79 \\
\hline & Parovarian cyst & 15 & 14.01 \\
\hline & Dermoid cyst & 13 & 12.14 \\
\hline & $\begin{array}{l}\text { Serus } \\
\text { cystadenoma }\end{array}$ & 12 & 11.21 \\
\hline & $\begin{array}{l}\text { Mucinous } \\
\text { cystadenoma }\end{array}$ & 5 & 4.67 \\
\hline & $\begin{array}{l}\text { Simple follicular } \\
\text { cyst }\end{array}$ & 6 & 5.60 \\
\hline & $\begin{array}{l}\text { Corpus luteal } \\
\text { cyst }\end{array}$ & 7 & 6.54 \\
\hline \multirow{5}{*}{$\begin{array}{l}\text { Per- } \\
\text { operative } \\
\text { complication }\end{array}$} & $\begin{array}{l}\text { Cyst rupture prior } \\
\text { to drainage }\end{array}$ & 18 & 16.82 \\
\hline & $\begin{array}{l}\text { Haemorrhage } \\
\text { from ovary }\end{array}$ & 6 & 5.60 \\
\hline & $\begin{array}{l}\text { Injury to the } \\
\text { omentum }\end{array}$ & 1 & 0.93 \\
\hline & $\begin{array}{l}\text { Injury to inferior } \\
\text { epigastric } \\
\text { Vessels }\end{array}$ & 1 & 0.93 \\
\hline & $\begin{array}{l}\text { Injury to the } \\
\text { bowel }\end{array}$ & 0 & 0 \\
\hline \multirow{3}{*}{$\begin{array}{l}\text { Post- } \\
\text { operative } \\
\text { complication }\end{array}$} & Fever & 24 & 22.42 \\
\hline & Port site infection & 12 & 11.21 \\
\hline & Port site fistula & 1 & 0.93 \\
\hline
\end{tabular}

Table-III: Tumour markers level $(n=107)$

\begin{tabular}{|l|l|l|l|l|}
\hline $\begin{array}{l}\text { Tumour } \\
\text { markers }\end{array}$ & Normal & Percentage & Raised & Percentage \\
\hline CA-125 & 83 & 77.57 & 24 & 22.42 \\
\hline CEA & 105 & 98.13 & 2 & 1.86 \\
\hline CA19-9 & 104 & 97.19 & 3 & 2.80 \\
\hline LDH & 106 & 99.06 & 1 & 0.93 \\
\hline
\end{tabular}

Table-IV: Surgical outcome of patients

\begin{tabular}{|l|l|}
\hline Mean operative time & 62.75 minutes \\
\hline Estimated blood loss & $39.62 \mathrm{ml}$ \\
\hline Postoperative Hb decreased & $0.71 \mathrm{gm} \%$ \\
\hline Mean hospital stay & 4.43 Days \\
\hline
\end{tabular}




\section{Discussion}

Benign ovarian tumour is one of the common entity which the gynaecologist has to treat. Most ovarian cysts are benign with malignancy found in only $7-13 \%$ of premenopausal women and 8-45\% of postmenopausal women ${ }^{6}$. Laparoscopic surgery is the most frequent indication for the management of benign ovarian cyst in the obstetrics and gynecological field7. Laparoscopy has been accepted for years as a management of benign ovarian tumour ${ }^{8}$. It is considered as the gold standard treatment for small to moderate size ovarian cyst but huge ovarian cyst can also be managed laparoscopically by experienced surgeon though there is possibility of cyst rupture and spillage of malignant cells. The procedure is associated with reduced operative blood loss, fewer postoperative complications, shorter hospitalization, less pain and earlier recovery compared with laparotomy 9,10 . In this case series maximum no, of women presented with ovarian cyst between the age of 21-30 years which is similar to another study by Zahra Fatimah et al11. The majority of the women had presenting complaints that resulted in a planned elective laparoscopic surgery whereas a total 24(22.42\%) pts presented with acute pain in the abdomen with suspicion of ovarian cyst accident such as torsion or haemorrhage and needed emergency operation.

Proper patients' selection is mandatory to minimize the risk of draining malignant tumour previous reports indicate that meticulous clinical and ultrasound examination of ovarian cysts can exclude most cases of ovarian malignancies ${ }^{12}$. Potential malignant tumour should be carefully excluded from laparoscopic options. This is performed by the use of transvaginal ultrasonography combined with where possible with Doppler and 3D ultrasound. In that cases parameters that have to be examined are diameter of the cyst larger than $5 \mathrm{~cm}$, presence of unilocular or bilateral ovarian cyst, septa and solid particles of papillomatous structure. Concerning tumour markers CA-125 has a special predictive value in premenopausal women even than false positive are expected in case of endometriosis and uterine fibroid 13 . In addition to tumour markers intraoperative inspection of the cysts prior to the drainage should reduce the risk further. In this case series CA-125 were found raised in $24(22.42 \%)$ patients where frozen section biopsy had been arranged but none found malignant.

In this study small to moderate size ovarian cysts ranging from 4$15 \mathrm{~cm}$ were managed laparoscopically. Maximum number of patients had cyst diameter of 4-6 cm (49.53\%), $41.12 \%$ had cyst diameter of $7-9 \mathrm{~cm}$ and (8.41\%) had cyst diameter of $10-12 \mathrm{~cm}$. However, there are several case reports where huge ovarian cyst measuring up-to 21-22 $\mathrm{cm}$ were also removed laparoscopically ${ }^{14,15}$. Most of the ovarian cysts were unilateral (91.5\%). Right ovary was involved in $(51.40 \%)$, left ovary in $(41.18 \%)$ cases and $(8.41 \%)$ were bilateral which coincides with other studies ${ }^{15,16}$. Cystectomy is the most common procedure performed in this case series as most of the patients were in the reproductive age group and ovaries had to preserved for future fertility. Salpingo-oophorectomy were done in $11(10.28 \%)$ patients due to torsion where there is no viable ovarian tissue and in older patient.

Laparoscopic approach is associated with a great risk of spillage of cyst contents ${ }^{16}$. In most of the cases cystic fluid were first drained and cyst cavity was thoroughly washed before removal of cyst wall completely. Cyst wall then retrieved through $10 \mathrm{~mm}$ port. In cases of dermoid cyst and endometrioma plastic bag is used to prevent spillage of cyst contents. Although the cyst contents can usually be removed by using careful technique and peritoneal ravage remaining cyst contents are known to cause chemical peritonitis in patients of dermoid cysts. Case reports have described severe chemical peritonitis that has resulted in significant pelvic adhesive disease, bowel obstruction, abdominal wall abscess and enterocutaneous fistula formation requiring multiple intensive medical management and repeat laparotomies ${ }^{17}$. In this study inadvertent cyst rupture before aspiration occurred in (16.82) \% cases specially in some cases of endometriomas and in two cases of dermoid cysts but thorough peritoneal wash with saline were done. Yuen et al18 report that the cyst was removed unruptured in $72.2 \%$ of the cases which was $83.18 \%$ in this study.

After getting histopathological report it was found that endometrioma is most common ( $45.79 \%$ which is similar to another study by D Jukie et al19, which was $80.6 \%$. In this study no one found to have malignancy on histopathological examination but another study among 61 patients by Mendilcioglu et a ${ }^{20}$ two patients are found to have malignancy. Mean operating time was 62.75 minutes which was comparable to the same study21 which was 67.2 minutes. In this study more time is required due to additional procedure like adhesiolysis, appendisectomyetc. Average hospital stay was 4.43 days and EBL was $39.62 \mathrm{ml}$ which was more or less similar to other studies ${ }^{19-21}$.

\section{Conclusion}

Laparoscopic surgery should be the preferred surgical approach in the management of benign ovarian cysts. With appropriate preoperative evaluation it is technically feasible, safe, and advantageous with minimal morbidity and should replace laparotomy in the management of most adnexal masses. Careful patient selection and proper surgical training are critical to ensure safe performance of laparoscopy.

\section{References}

1. Medeiros LR, Rosa DD, Bozzettic M C et al. Laparoscopy vs Laparotomy for benign ovarian tumour. Cochrane database sys Rev2009; 2:CD004751.

2. Canis $M$, Botchorishvili $\mathrm{R}$, ManhesH et al. Management of adnexal masses. Role and risk of laparoscopy. Semin Surg Oncol 2000; 19(1):28-35.

3. Hilger WS, Magrina JF, Magtibay PM. Laparoscopic management of the adnexal mass.Clinical Obstetrics and gynecology 2006; 49(3):535-48.

4. Alobaid A, Memon A, Alobaid S et al. Laparoscopic management of huge ovarian cysts. Obstetrician and Gynecology International 2013: 380854 .

5. Grammatikakis I, Trompoukis P, Zervoudis S et al. Laparoscopic treatment of 1522 adnexal masses- An 8 years experience. Diagnostic and Theraputic Endoscopy 2015:1-4.

6. Parker WH, Berek JS. Laparoscopic management of adnexal masses,Obstetrics and Gynecology clinics of north America1994; 21:79-92.

7. Imme A Caglia P, GandolfoL et al. Laparoscopic treatment of benign ovarian cyst. Chir Ital 2002; 54(4):533.

8. Leng JH, Lang JH, Zhang JJ et al. Role of laparoscopy in the diagnosis and treatment of adnexal masses. Chin Med J(Engl) 2008; 119(3):202-6. 
9. Vishwanath V, Jyotis G, Patil KV et al. Laparoscopic Management Of Large Ovarian Cyst at a Rural Hospital. J Gynecol Endosc Surg 2009; 1(2):94-7.

10. Eltabbakh GH, Charboneau AM, Eltabbakh NG. Laparoscopic Surgery For Large Ovarian Cyst. Gynecol Oncol 2008; 108:72-6.

11. Zahra F. Pattern of benign ovarian cyst in Qatary women. Qater Med J 2017; 2016(2):17.

12. Bruhat MA, Mage G, Bagory $G$ et al. Laparoscopic treatment of ovarian cysts. Indication, techniques, results. Apropos of 650 cases. Chirugie 1992; 117(5-6):39.

13. Matsushila H, Watanabe K, Yokoi T et al. Unexpected ovarian malignancy following laparoscopic excision of adnexal masses. Human reproduction 2014; 29(9):1912-7.

14. Michael L, Stitely MD. Laparoscopic removal of large ovarian mass utilizing planned trocar puncture. Journal of the society of laparoscopic surgeon 2012; 16:148-50.

15. Love BR, Murray G. Ovarioscopy and Laparoscopic removal of Large Rt adnexal cyst. JSLS 2010; 14(1):123-5.
16. Alireza A, Shamshirsaz, Amirhoushang A. Laparoscopic management of chemical peritonitis caused by Dermoid cyst spillage. JSLS2011; 15(3):403-5.

17. Malhotra A, Grimes C, Nikolic M et al. Severe granulomatous peritonitis and small bowel fistula formation following the excision of an ovarian dermoid cyst. A case report Gynecol Surg 2008; 5:157-9.

18. Yuen PM, Rogers MS. Laparoscopic management of ovarian masses- the initial experience and learning curve. Australian and Newzealand Journal of Obstetrics and Gynaecology 1994; 34(2):191-4.

19. Djukie M, Stankovic Z, Vasiljevic M et al. Laparoscopic management of ovarian benign masses. Clinical and Experimental Obstetrics \& Gynecology 2014; 41(3):296-9.

20. Lok IH, Sahota DS, Rogers MS et al. Complication of laparoscopic surgery for benign ovarian cyst. J Am Assoc Gynecol Laparosc 2000; 7(4):529-34.

21. Mendilcioglu I, Zorlu CG, Trak B et al. Laparoscopic management of adnexal masses, Safety and Effectiveness. J Reprod Med 2002; 47(1):36-40. 